\title{
Interactions of Plant Microbiomes: A Review on the Azospirillum brasilense
}

\author{
Alessandra Maria De Lima Naoe ${ }^{1 *}$, Lucas Koshy Naoe² and Joênes Mucci Peluzio \\ 'Department of Agricultural Research, Federal University of Tocantins, Palmas, Brazil \\ ${ }^{2}$ State University of Tocantins, Palmas, Brazil
}

*Corresponding author: Alessandra Maria de Lima Naoe, Department of Agricultural Research, Federal University of Tocantins, Palmas, Brazil

\begin{abstract}
The interactions that control the microorganism-soil-plant system are complex and difficult to understand. Currently, the knowledge about these interactions has allowed us to know a range of beneficial microorganisms and use them as sustainable agricultural production techniques. In addition to improving the anatomy of plants, these microorganisms can increase the tolerance of plants against attack by pathogens and abiotic stresses, such as drought stress, a good example is the bacterium Azospirillum brasilense. Inoculation with this bacterium has been identified as a low-cost biotechnological technique to improve crop productivity.
\end{abstract}

Keywords: Azospirillum brasilense; Rhizobacteria; Stress Environmental and Sustainable Agriculture

\section{Introduction}

In recent years, there has been a great advance in knowledge about the composition of soil microbiomes and their dynamics. There is evidence that plants shape the structures of the microbiome, most probable by root exudates, and also that the microbiota has developed several adaptations to establish in the rhizospheric niche [1]. Thus, it can be said that plants and microorganisms evolved simultaneously. Beneficial interactions between plants and microorganisms are classified by commensalism, mutualism and symbiosis. Commensalism is a unidirectional interaction between microorganisms, in which one population is benefited and the other is not affected. Mutualism is an interaction in which mutual benefits occur, as in the interaction between plants and bacteria of the genus Azospirillum. In the case of symbiosis, there are also mutual benefits, but the association is mandatory, due to a symbiosis between the microorganism and the host plant [2].

One of the main benefits of ecological interactions refers to the availability of nutrients, especially by biological nitrogen fixation (BNF). An example are the bacteria of the genus Bradyrhizobium, which, when they come into contact with the root system, cause infection in the roots with the formation of nodules, enabling the absorption of nitrogen by the plant [3]. Another important effect observed in the interactions is in the growth and anatomy of the plants. The literature widely reports the benefits of plant growthpromoting rhizobacteria (PGPRs).

In addition, there is evidence that this association promotes tolerance to abiotic stresses in plants, in this context the genus Azospirillum shows good results [4]. Thus, the study of ecological relationships and their effects on the development of plants has made it possible, over time, to isolate organisms of agricultural interest. However, many mechanisms that govern these interactions are unknown.

\section{Plant Growth-Promoting Rhizobacteria (PGPR): Azospirillum brasilense}

In their natural environment, plants are part of a rich ecosystem, which includes many microorganisms in the soil and covers a range of ecological possibilities. The different groups of microorganisms present in the soil play important roles, which can positively or negatively influence the development of plants and the interactions established by them [5]. Among them, bacteria represent approximately $95 \%$ of the all microbiota present in the environment, being found in greater numbers in the rhizosphere of plants [6]. Among the bacteria found in the soil, rhizobacteria have great potential in agriculture. These organisms are free-living and can be found colonizing the roots and / or 
internal tissue of plants, exercising symbiotic, endophytic or associative relationships [6].

These bacteria, when associated with plants, have the ability to promote their growth, this occurs in two ways. Directly, facilitating the acquisition of resources or modulating the levels of plant hormones, or indirectly, decreasing the inhibitory effects of pathogens on the plant, acting as a biocontrol. The production of phytohormones is one of the main mechanisms to explain the beneficial effects of PGPRs. The synthesis of phytohormones such as auxins [7], cytokinins [8], gibberellins [9] and abscisic acid [10], acts in the development of plants under specific conditions. Among the auxins, indole-3-acetic acid (IAA) is cited as the compound produced in greater quantity by PGPRs. It is important to note that the synthesis of phytohormones in bacteria depends on the presence of precursors in the root exudates in a complex feedback relationship.

The mechanisms by which PGPRs influence plant growth can also differ between species and strains of the microorganism. Factors such as plant species, soil type and environmental conditions are also determinant variables in the success of colonization and interaction between organisms. Another important aspect is that PGPRs can act as protection against abiotic stresses in plants [11]. This mechanism would be related to the substantial increase in the root area, which improves the efficiency in the removal of water and nutrients by the plants.

The application of these microorganisms in agriculture as a sustainable practice is already a reality in many countries. This type of biotechnology represents an important strategy to mitigate adverse effects from the use of chemical fertilizers. One of the main species of interest is Azospirillum brasilense. The Azospirillum genus comprises plant growth promoting bacteria, which have been widely studied. Currently, twenty species have already been described, with Azospirillum brasilense being the one with the highest number in genetic and physiological studies [12].

Azospirillum brasilense is a free-living, gram negative and diazotrophic bacterium that can colonize the rhizosphere and internal tissues of plants. For a long time, the benefits attributed to inoculation with this bacterium were recognized only by its ability to fix atmospheric nitrogen. However more recent studies have observed that only a fraction of this nitrogen was transferred to the plant [13]. Other benefits have been described over time, such as the synthesis of phytohormones [14], phosphate solubilization [15] protection against pathogens [16] and reduced effects of abiotic stress [17], all of which are directly or indirectly related to plant growth.

The bacterium has many mechanisms to promote plant growth, [13] proposed the "theory of multiple mechanisms" in which the bacteria acts in a cumulative way or sequential pattern of effects, resulting from mechanisms that occur simultaneously or consecutively [13]. Phytohormone synthesis is perhaps the most important mechanism, as it coordinates various physiological and biochemical processes in the plant. The response observed in the growth of plants inoculated with Azospirillum brasilense was mainly attributed to the activity of indole-3-acetic acid (IAA) in the root system [14]. IAA has been described as the phytohormone produced in greater quantity by Azospirillum brasilense and its synthesis has a high degree of similarity with plant biosynthesis [18]. In addition, it was observed that these bacteria can induce the synthesis of hormones by the plant, more increasing the concentration of these compounds in the medium [13].

The most significant results of the interaction with Azospirillum brasilense were observed when changing the root architecture. Inoculation can promote root elongation $[19,20]$, development of lateral and adventitious roots $[21,22]$ and root hair [23]. It is generally accepted that these developmental responses in root morphology are activated by phytohormones. Changes in root morphology are closely related to tolerance to abiotic stresses, such as low water availability. This mechanism has already been observed in many studies $[17,24,25]$ that proved that plants inoculated with Azospirillum brasilense have greater drought tolerance.

Anyway, it is uncertain to say that drought tolerance is related only to changes in the root. Using the "theory of multiple mechanisms" it can be said that other factors are involved in this process. Studies conducted by [17] and [26], attributed drought tolerance mainly to the increase in the synthesis of the abcysic acid hormone (ABA) by Azospirillum brasilense. $A B A$ is known to be an important signal in cases of water stress.

Although there is evidence of increased phytohormone production in plants inoculated with Azospirillum brasilense, it is important to note that the results do not always reflect increased productivity [27]. In addition, divers studies have shown no correlation between the capacity for phytohormone synthesis by Azospirillum brasilense and the effects on root growth [28]. Therefore, it is necessary that studies continue seeking information on the mechanisms of interaction between the bacteria and its effects on plant growth and development. 


\section{Conclusion}

The use of PGPRs in agriculture represents an advance in management techniques, bacteria of the genus Azospirillum are recognized to be beneficial to plants, however, it is necessary to understand the multifactorial mechanisms of interaction, so that the technique is better understood and improved.

\section{References}

1. Jacoby R, Peukert M, Succurro A, Koprivova A, Kopriva S (2017) The Role of Soil Microorganisms in Plant Mineral Nutrition Current Knowledge and Future Directions. Frontiers in Plant Science (8): 1-19.

2. Leite LFC, Araújo, ASF (2011) Ecologia microbiana no solo. Embrapa Meio Norte (Documento 164).

3. Silva AF, Carvalho MAC, Schoninger EL, Monteiro S, et al. (2011) Doses de inoculante e nitrogênio na semeadura da soja em área de primeiro cultivo. Bioscience Journal 27(3): 404-412.

4. Cassán F, Vanderleyden J, Spaepen S (2013) Physiological and agronomical aspects of phytohormone production by model plantgrowth-promoting rhizobacteria (PGPR) belonging to the genus Azospirillum. Journal of Plant Growth Regulators 32(3): 440-459.

5. Delaux PM, Radhakrishnan G, Oldroyd G (2015) Tracing the evolutionary path to nitrogen-fixing crops. Curr. Opin. Plant Biol 26: 95-99.

6. GlickBR (2012)PlantGrowth-Promoting Bacteria: Mechanisms and Applications. Hindawi Publishing Corporation, Scientifica $16 p$.

7. Spaepen S, Vanderleyden J (2011) Auxin and plant-microbe interactions. Cold Spring Harbor perspectives in biology 3(4): a001438.

8. Tien T, Gaskins MH, Hubbell DH (1979) Plant growth substances produced by Azospirillum brasilense and their effect on the growth of pearl millet (Pennisetum americanum L.) Applied and Environmental Microbiology 37: 1016-1024.

9. Bottini R, Fulchieri M, Pearce D, Pharis RP (1989) Identification of gibberellins $A 1, A 3$ and iso-A3 in cultures of Azospirillum lipoferum. Plant Physiol 90: 45-47.

10. Cohen AC, Bottini R, Piccoli PN (2008) Azospirillum brasilense Sp 245 produces ABA in chemically-defined culture medium and increases $A B A$ content in Arabidopsis plants. Plant Growth Regul 54: 97-103.

11. Dimkpa C, Weinan T, Asch F (2009) Plant-rhizobacteria interactions alleviate abiotic stress conditions. Plant, Cell and Environment 32(12): 1682-1694.

12. Fukami J, Cerezini P, Hungria M (2018) Azospirillum: benefts that go far beyond biological nitrogen fixation. AMB Express 8(1): 73.

13. Bashan Y, De-Bashan LE (2010) How the plant growthpromoting bacterium Azospirillum promotes plant growth-a critical assessment. Advances in Agronomy 108: 77-136.

14. Molina R, Rivera D, Mora V, López G, Rosas S, et al. (2018) Regulation of IAA Biosynthesis in Azospirillum brasilense
Under Environmental Stress Conditions. Current Microbiology 75(10): 1408-1418.

15. Turan M, Gulluce M, Wirén NV, Sahin F (2012) Yield promotion and phosphorus solubilization by plant growth promoting rhizobacteria in extensive wheat production in Turkey. J Plant Nutr Soil Sci 175: 818-826.

16. Bashan Y, De-Bashan LE (2002) Reduction of bacterial speck (Pseudomonas syringae pv tomato) of tomato by combined treatments of plant growth-promoting bacterium, Azospirillum brasilense, streptomycin sulfate, and chemothermal seed treatment. Eur. J. Plant Pathol 108: 821-829.

17. Cohen AC, Bottini R, Pontim MN, Berli FJ, Moreno D, et al. (2015) Azospirillum brasilense ameliorates the response of Arabidopsis thaliana to drought mainly via enhancement of ABA levels. Physiologia Plantarum Journal 153: 79-90.

18. Spaepen S, Vanderleyden J, Remans R (2007) Indole-3-acetic acid in microbial and microorganism-plant signaling. FEMS Microbiology Reviews 31(4): 425-448.

19. Dobbelaere S, Croonenborghs A, Thys A, Broek A, Vanderleyden J (1999) Phytostimulatory effect of Azospirillum brasilense wild type and mutant strains altered in IAA production on wheat. Plant Soil 212: 155-164.

20. Levanony $H$, Bashan $Y$ (1989) Enhancement of cell division in wheat root tips and growth of root elongation zone induced by Azospirillum brasilense. Cd. Can. J. Bot 67: 2213-2216.

21. Creus CM, Graziano M, Casanovas EM, Pereyra MA, Simontacchi M, et al. (2005) Nitric oxide is involved in the Azospirillum brasilense-induced lateral root formation in tomato. Planta 221(2): 297-303.

22. Molina-Favero C, Creus CM, Simontacchi M, Puntarulo S, Lamattina L (2008) Aerobic nitric oxide production by Azospirillum brasilense Sp245 and its influence on root architecture in tomato. Mol. Plant Microbe Interact 21: 10011009.

23. Hadas R, Okon Y (1987) Effect of Azospirillum brasilense inoculation on root morphology and respiration in tomato seedlings. Biol. Fertil. Soils 5: 241-247.

24. Hungria M, Nogueira MA Araujo RS (2013) Tecnologia de Coinoculação da Soja com Bradyrhizobium e Azospirillum: incrementos no rendimento com sustentabilidade e baixo custo. Resumos da XXXIII Reunião de Pesquisa de Soja da Região Central do Brasil. Londrina.

25. Lima Naoe AM, Peluzio JM, Campos LJM, Naoe LK, Silva RA (2020) Co-inoculation with Azospirillum brasilense in soybean cultivars subjected to water defcit. Revista Brasileira de Engenharia Agrícola e Ambiental 24(2): 89-94.

26. Zahedi H, Abbasi S (2015) Effect of plant growth promoting rhizobacteria (PGPR) and water stress on phytohormones and polyamines of soybean. Indian Journal. Agriculture Research 49: 427-431.

27. Okon Y, Labandera-Gonzalez CA (1994) Agronomic applications of Azospirillum: an evaluation of 20 years wordwide field inoculation. Soil Biology and Biochemistry, Oxford 26: 1591-1601.

28. Bothe H (1992) Differential effects of Azospirillum, auxin and combined nitrogen on the growth of the roots of wheat. Symbiosis 13: 167-179. 
*Corresponding author: Alessandra Maria de Lima Naoe,Email: alima@uft.edu.br

Next Submission with BGSR follows:

- Rapid Peer Review

- Reprints for Original Copy

- E-Prints Availability

- Below URL for auxiliary Submission Link: https://biogenericpublishers.com/submit-manuscript/ 